\title{
A estrutura básica como objeto da justiça: liberdades básicas e as bases sociais do autorrespeito
}

\author{
The basic structure as the object of justice: basic freedoms and \\ the social bases of self-respect
}

\author{
Denilson Luis Werle \\ dlwerle@yahoo.com.br \\ (Universidade Federal de Santa Catarina, Santa Catarina, Brasil)
}

Resumo: 0 artigo parte do pressuposto de que para fazer um diagnóstico das injustiças, vulnerabilidades e carências das pessoas uma teoria crítica da justiça deve tomar como ponto de partida a posição real das pessoas no mundo, seus contextos de socialização e suas relações sociais de interdependência. Para isso, o objeto primário de uma teoria da justiça não deve ser diretamente os indivíduos e suas capacidades, mas sim a estrutura básica da sociedade, formada pelas principais instituições sociais, econômicas e políticas, isto é, os contextos intersubjetivos das relações interpessoais de cooperação social e de socialização que são determinantes na vida concreta das pessoas e principalmente na realização igual de suas liberdades e na formação do sentido interno do que significa ser autônomo.

Palavras-chave: estrutura básica, liberdades iguais, bases sociais do autorrespeito, John Rawls.
Abstract: The article starts from the assumption that in order to make a diagnosis of injustices, vulnerabilities and needs of people a critical theory of justice must take as its starting point the real position of people in the world, their contexts of socialization and social relations of interdependence. For this, the primary object of a theory of justice should not be individuals and their capabilities, but the basic structure of society, formed by the major social, economic and political institutions, i.e. intersubjective contexts of interpersonal relations of cooperation social and socialization that are determinant to the concrete life of the persons and especially to the realization of equal liberties and to the formation of the internal sense of what it means to be autonomous.

Keywords: basic structure, equals liberties, social basis of self-respect, John Rawls. 


\section{Introdução}

A publicação de Uma ideia de justiça, de Amartya Sen, colocou em tela, entre outras coisas, uma questão central para uma teoria crítica da justiça social: em vez de insistir no normativismo abstrato centrado nas estruturas institucionais de uma sociedade justa bem-ordenada, Sen enfatiza que uma teoria da justiça deve ter como objeto a posição real das pessoas no mundo, seus padrões de comportamento e as circunstâncias socioeconômicas concretas em que vivem. $\mathrm{O}$ objeto de uma teoria da justiça deve ser a vida que as pessoas são realmente capazes de levar, por meio de um diagnóstico das injustiças corrigíveis a serem identificadas por uma análise real das assimetrias produtoras dessas injustiças na vida das pessoas reais. "A justiça está fundamentalmente conectada ao modo como as pessoas vivem e não meramente à natureza das instituições que a cercam". ${ }^{1}$

Um dos propósitos centrais da Ideia de justiça é fornecer as bases metodológicas de uma abordagem da justiça que nos permita ir além do que chamou de "institucionalismo transcendental" (que incluiria autores como Hobbes, Locke, Rousseau, Kant e mais recentemente Habermas e Rawls). O principal alvo das críticas de Sen é a teoria da justiça de Rawls, embora reconheça alguns de seus méritos indiscutíveis: a ideia de equidade, a concepção de objetividade na razão prática baseada na ideia de razão pública, a concepção de pessoa moral dotada de senso de justiça e uma concepção do bem, a importância das liberdades básicas, a ênfase na igualdade de oportunidades, a atenção voltada às dificuldades das pessoas em pior situação (as políticas públicas de redução da pobreza), e a concepção dos bens primários, na qual "Rawls reconhece indiretamente a importância da liberdade humana em dar às pessoas oportunidades reais - por oposição àquelas apenas formalmente reconhecidas - para fazerem o que bem entendam com suas próprias vidas". ${ }^{2}$

No entanto, teria faltado a Rawls dar esse passo de forma mais explícita em direção às capacidades e oportunidades reais das pessoas. Para Sen a abordagem de Rawls apresenta algumas dificuldades que precisam ser examinadas. A primeira delas é a sua ênfase exagerada na

1. SEN, A. A ideia de justiça. Tradução de Denise Bottmann e Ricardo Doninelli Mendes. São Paulo: Companhia das Letras, 2011, pp. 12-13.

2. Idem, p. 95 . 
prioridade lexicográfica da liberdade. "Por que deveríamos considerar a fome coletiva, a fome individual e a negligência médica invariavelmente menos importante do que a violação de qualquer tipo de liberdade pessoal?". ${ }^{3}$ Rawls não teria dado a devida atenção às capacidades que as pessoas têm de converter bens primários numa prática de viver bem, o que muitas vezes pode colocar a liberdade em segundo plano. Rawls teria avaliado as oportunidades das pessoas apenas através dos meios que possuem, quando o que é relevante são precisamente as capacidades das pessoas em converterem bens primários em oportunidades reais de fazer coisas diversas com eles. Para pensar essa questão, uma teoria da justiça deveria mudar seu enfoque: ao invés dos bens primários, o foco deveria estar voltado para uma avaliação real das liberdades e capacidades das pessoas.

Claro, não se trata de um "afastamento fundamental do próprio programa de Rawls, mas de um ajuste na estratégia da razão prática". ${ }^{4}$ O que é central no raciocínio prático sobre a justiça social é a combinação entre a aplicação de princípios de justiça nas instituições e o comportamento real das pessoas. Isso implica abandonar as preocupações de uma abordagem contratualista (bem como a do utilitarismo, que aposta em respostas corretas às questões da justiça a partir do critério único da utilidade) e adotar uma abordagem intermediária: uma interpretação mais refinada da teoria da escolha social à luz dos insights inovadores fornecidos, por exemplo, pela figura do espectador imparcial de Smith, baseado no modelo de uma imparcialidade aberta mais frutífero do que o da imparcialidade fechada de cunho kantiano/rawlsiano. "O espectador imparcial de Adam Smith é naturalmente um dispositivo para o escrutínio crítico e a discussão pública. Ele não precisa, portanto, buscar a unanimidade ou um acordo total da mesma maneira que a camisa de força institucional que a teoria rawlsiana exige". ${ }^{5}$ Além de incluir aspectos normativos sobre a justiça equidade, reciprocidade e imparcialidade - a perspectiva do espectador imparcial permite ver como as questões se apresentam "aos olhos de outras pessoas, da perspectiva de espectadores reais - distantes e próximos". ${ }^{\prime 6}$

3. Idem, p. 96.

4. Idem, p. 97.

5. Idem, p. 165

6. Idem, p. 167. 
Para detectar quais aspectos do mundo e da vida humana uma teoria da justiça deveria levar em conta para fazer seu diagnóstico crítico da sociedade e avaliar as situações de injustiça e procurar promover a justiça, defende que o foco informacional da teoria da justiça está fundado numa "abordagem das capacidades, baseada na liberdade", 7 em contraste com abordagens alternativas baseadas apenas nos recursos e meios ou na utilidade. A liberdade diz respeito, portanto, às nossas capacidades reais para determinarmos o que queremos, o que valorizamos e o que decidimos fazer. Portanto, no diagnóstico crítico da sociedade, as assimetrias das capacidades desempenham um papel central na avaliação das disparidades sociais, e a promoção da justiça requer a expansão das capacidades humanas de todos os membros da sociedade na forma de oportunidades reais de liberdade e exercício da autonomia (sem recorrer, contudo, a um plano ideal pré-concebido). As capacidades não são uma espécie de fita métrica da justiça: esta não exige, por exemplo, que cada um tenha um conjunto igual de capacidades. As capacidades são simplesmente uma importante fonte informacional para as nossas escolhas sociais e os nossos juízos sobre a justiça devem levar em conta uma pluralidade de características diferentes de nossas vidas e de nossos interesses.

As variadas realizações de funcionamentos humanos que podemos valorizar são muito diversas, variando desde estar bem nutrido ou evitar a morte precoce até tomar parte da vida da comunidade e desenvolver a aptidão para seguir os planos e as ambições ligados ao trabalho. ${ }^{8}$

A liberdade como capacidade consiste, então, "no potencial de fazer combinações diversas de funcionamentos que possamos comparar e julgar entre si com relação àquilo que temos razão para valorizar" ${ }^{9}$. Toda preocupação com a promoção da justiça deve se concentrar na

7. Idem, p. 265.

8. Idem, p. 267.

9. Idem, ibidem. Sen pressupõe aqui que o leitor esteja familiarizado com os conceitos capacidades, funcionamentos e agência, apresentados em livros e textos anteriores, e que não são claramente desenvolvidos no livro. As capacidades são definidas derivadamente a partir de funcionamentos e elas consistem em combinações diferentes de funcionamentos, na liberdade substantiva que a pessoa desfruta para levar o tipo de vida que julga razoável. Os funciona- 
vida humana, deslocando do foco nos meios da vida para as oportunidades reais de vida. Essa é a chave também para uma compreensão mais apropriada da liberdade. Ela tem de ser entendida como liberdade substantiva, como oportunidades reais para definir determinados fins de modo razoável e realizá-los. Ser uma pessoa livre significa ser capaz de poder fazer realmente boas escolhas e poder levar adiante sua realização.

Mas, qual é o critério para definir uma boa escolha? Espera-se que uma boa escolha seja feita de forma autônoma, sem a arbitrariedade da coerção e da opressão. Sen dá prioridade a uma noção de liberdade que só faz sentido se a escolha dos fins da ação for a expressão de uma avaliação refletida baseada no raciocínio e argumentação pública sobre a importância relativa do que queremos fazer. "É preciso reconhecer a importância do exercício da razão pública como forma de estender o alcance e a confiabilidade das valorações e de torná-las mais robustas". ${ }^{10}$

O pressuposto geral da argumentação de Sen é o de que o cerne normativo de uma teoria da justiça consiste em assegurar a autonomia dos indivíduos e que, consequentemente, a tarefa de uma teoria da justiça é fazer com que a estrutura básica da sociedade esteja arranjada de modo a reduzir as vulnerabilidades relacionadas àquela autonomia a um mínimo social aceitável. As teorias da justiça fundadas nos ideais da tradição do "institucionalismo transcendental" fracassam em sua missão principal por não levarem em conta as várias e diferentes

mentos são as ações (comer, frequentar a escola, viver em associações e participar da vida política etc.) ou estados de bem-estar (estar bem nutrido e saudável, ter uma vida segura e uma amizade calorosa, um bom emprego etc.) consideradas valiosas. A agência refere-se à habilidade da pessoa em buscar e realizar objetivos que julga racionalmente valiosos, e está relacionada a outros conceitos como o de autoconsciência, autorrealização, autonomia e autodeterminação. A preocupação com a agência significa que a participação, o debate público e o empoderamento social devem ser promovidos ao lado da preocupação com o bem-estar. Cf. SEN, A. Development as freedom. New York: Knopf Press, 1999; NUSSBAUM, M. C. Women and buman development. The capabilities approach. Cambridge: Cambridge University Press, 2000; CROCKER, D. Functioning and capability. The foundations of Sen's and Nussbaum's development ethic. Political Theory, v.20, n.4, 1992, p. 584611.

10. SEN, A. A ideia de justiça, p. 276. 
ameaças à autonomia e, com isso, subestimam as vulnerabilidades as quais estão sujeitos os indivíduos em sua vida social.

No caso mais específico do liberalismo político, uma crítica típica é a de que ele defende uma concepção de autonomia e de liberdade por demais individualista, o que acaba levando a uma idealização enganosa dos indivíduos como sujeitos autossuficientes e autoconfiantes, e não consegue, por isso, interpretar adequadamente as exigências da justiça social, não considerando as carências, as vulnerabilidades e as relações de interdependência que marcam a vida social dos indivíduos. Para sanar este problema, algumas interpretações críticas pretendem ampliar as exigências da justiça social a partir de uma concepção ampliada de autonomia que vai além de suas circunstâncias institucionais e materiais: a autonomia tem de ser entendida como uma capacidade que existe somente no contexto das relações sociais que a asseguram e somente em conjunção com o sentido interno do que significa ser autônomo. ${ }^{11}$ A ideia central dessa concepção de autonomia é a de que as pessoas, para agirem de forma autônoma, além das condições materiais e institucionais, têm de ser capazes de manter certas atitudes positivas em relação a si mesmas (de autoconfiança, autorrespeito e autoestima), que dependem de processos sociais de interação e de relações interpessoais de reconhecimento bem sucedidas.

Esse tipo de deficiência, apontado por diversos teóricos comunitaristas e autoras feministas, atinge uma parte significativa dos teóricos liberais. Porém, não parece fazer jus à concepção de justiça elaborada por Rawls, que, como apontam Honneth e Anderson, tem "recursos impressionantes" para lidar com as dimensões intersubjetivas da autonomia. No que se segue pretendo tornar isso mais claro ao recordar que o objeto primário de uma teoria da justiça não são diretamente os indivíduos e suas capacidades, mas sim a estrutura básica da sociedade, formada pelas principais instituições sociais, econômicas e políticas, isto é, o contexto intersubjetivo das relações interpessoais de cooperação social e de socialização dos indivíduos, que é determinante na vida concreta das pessoas e principalmente para a realização igual de suas liberdades. Pretendo tornar isso mais evidente ao apresentar os argumentos desenvolvidos por Rawls para justificar o sentido da ideia de liberdades básicas e sua prioridade em conexão com a

11. HONNETH, A.; ANDERSON, J. Autonomy, vulnerability, recognition and justice. In: CHRISTMAN, J.; ANDERSON, J. Autonomy and the challenges to liberalism: new essays. Cambridge: Cambridge University Press, 2005, p. 126. 
ideia mais fundamental das bases sociais do autorrespeito: "só faz sentido que as partes incluam o bem intersubjetivo básico do autorrespeito em suas deliberações sobre a estrutura básica de uma sociedade justa se eles já compreenderam que a concepção e a persecução de seus planos de vida dependem fundamentalmente da estima dos outros". ${ }^{12} \mathrm{O}$ que se pode argumentar é que a própria concepção de liberdades básicas é justificada a partir das bases sociais do autorrespeito. ${ }^{13}$ Esta é uma das razões pelas quais o objeto de uma teoria da justiça é a estrutura básica da sociedade, tanto para pensar a realização da justiça por meio de um sistema igual de liberdades fundamentais como para identificar as causas mais profundas da produção das vulnerabilidades e carências relacionada à autonomia das pessoas.

\section{O sentido das liberdades básicas e a justificação de sua prioridade}

Diferentemente de um liberalismo mais tradicional, a teoria da justiça de Rawls articula diferentes dimensões da liberdade, sem que uma esteja subordinada a outra. Na formulação de Rawls a determi-

12. Idem, p. 142. Honneth e Anderson pretendem justamente aprimorar a abordagem básica de Rawls, e não se afastar dela. Para isso, sugerem três revisões no modelo de Rawls para acomodar a concepção de autonomia baseada no reconhecimento: 1) ele precisa ser mais aberto a considerações baseadas naquilo que sabemos sobre as pessoas humanas, 2) ele precisa tratar mais extensamente dos modos pelos quais a infraestrutura do reconhecimento da sociedade pode deixar a autonomia dos indivíduos inaceitavelmente vulnerável, e 3) é preciso admitir que a ênfase nas relações sociais de reconhecimento exige um afastamento de questões exclusivamente distributivas. Para ver se Honneth e Anderson realmente conseguem se afastar da concepção de Rawls, cf. o excelente artigo de BANKOVSKY, M. Social justice: defending Rawls' theory of justice against Honneth's objections. Pbilosopby \& Social Criticism, v. 37, n. 1, 2011, pp. 95-118.

13. É importante ter em mente que o autorrespeito não desempenha somente esse papel na teoria da justiça de Rawls. Para além da justificação das liberdades básicas, Rawls recorre à noção de autorrespeito para reforçar o argumento da estabilidade. Rawls "argues that justice as fairness is a stable conception of justice because it cultivates and supports individual's self-respect in the most reliable way. As a result, individuals in a society organized by his principles of justice will be psychologically disposed and motivated to uphold those principles and institutional arrangements that have so effectively underwritten their sense of self-worth". ZINK, J. R. Reconsidering the role of self-respect in Rawls's A theory of justice. The Journal of Politics, v. 73, n.2, 2011, p. 331-332. 
nação do sistema adequado de liberdades fundamentais não pode ser pensada como tendo a função de maximizar um valor absoluto (a liberdade como tal); antes, trata-se de justificar um conjunto de liberdades fundamentais necessárias para o desenvolvimento adequado das capacidades razoáveis e racionais da pessoa autônoma, como membro pleno de uma sociedade democrática.

Na conferência VIII do Liberalismo Político (2011) Rawls afirma que foi levado a modificar sua explicação da liberdade a partir da crítica que lhe foi feita por Hart no artigo Rawls on Liberty and its priority.$^{14}$ Hart apontou duas falhas graves no argumento de Rawls: 1) que as razões pelas quais as partes na posição original adotariam as liberdades básicas e concordariam com sua prioridade não estavam suficientemente explicitadas em Uma Teoria da Justiça, 2) que quando os princípios de justiça são aplicados nos estágios constitucional, legislativo e judicial não é fornecido um critério suficiente para saber como as liberdades básicas devem ser especificadas e ajustadas umas às outras quando são conhecidas as circunstâncias sociais da sociedade. Rawls pretende corrigir essas duas falhas tornando mais preciso o argumento a favor dos dois princípios de justiça, mostrando como as liberdades básicas e os fundamentos para sua prioridade podem ser justificados a partir da concepção de cidadãos como pessoas livres e iguais em conjunto com uma explicação dos bens básicos e uma certa concepção de cooperação social.

Para dar uma resposta consistente a Hart, Rawls começa reformulando os princípios de justiça e esclarecendo qual o conceito de pessoa que está na base da sua concepção de justiça. Os dois princípios passam a ter a seguinte formulação:

a. Cada pessoa tem um direito igual a um sistema plenamente adequado de liberdades fundamentais que seja compatível com um sistema similar de liberdade para todos.

b. As desigualdades sociais e econômicas devem satisfazer duas condições. A primeira é que devem estar vinculadas a cargos e posições abertos a todos, em condições de igualdade equitativa de

14. HART, H. L. A. Rawls on liberty and its priority. In: DANIELS, N. (ed.). Reading Rawls. Critical studies of A Theory of Justice. Oxford: Basil Blackwell, 1975, pp. 230-252. 
oportunidades: a segunda é que devem redundar no maior benefício possível para os membros menos privilegiados da sociedade. ${ }^{15}$

A alteração ocorre principalmente no primeiro princípio, onde a expressão "mais abrangente sistema total", presente na primeira formulação do princípio em Uma teoria da justiça, é substituída por "sistema plenamente adequado", e também é inserida "que seja" antes da palavra "compatível". O propósito dessa reformulação é mostrar justamente que "nenhuma prioridade é atribuída à liberdade como tal, como se o exercício de alguma coisa denominada 'liberdade' tivesse valor preeminente e pudesse ser o fim principal, se não o único, da justiça social e política". ${ }^{16}$ Se assim fosse, o liberalismo político de Rawls acabaria sendo igual aos demais liberalismos éticos-políticos que defendem algum tipo de ideal moral abrangente.

O liberalismo político de Rawls não é abrangente justamente pelo modo como fundamenta as liberdades básicas. Rawls fornece uma lista dessas liberdades fundamentais iguais no primeiro princípio de justiça: a liberdade de pensamento e de consciência; as liberdades políticas e a liberdade de associação, assim como as liberdades especificadas pela liberdade e integridade da pessoa ${ }_{i}$ e, finalmente, os direitos e liberdades abarcados pelo império da lei, não atribuindo ou justificando nenhuma forma de hierarquização entre elas. O que importa é a formação e institucionalização de um sistema das liberdades, que permanece em certa medida indeterminado quanto à combinação das várias liberdades conflitantes. Ao dizer que não atribui nenhuma prioridade à liberdade como tal, Rawls argumenta que sua interpretação das liberdades fundamentais segue a tradição do pensamento democrático, cujo foco sempre esteve voltado para "alcançar certas liberdades e garantias constitucionais, com aquelas encontradas em diferentes cartas de direitos e declarações dos direitos do homem". ${ }^{17}$ Dado que as várias liberdades fundamentais estão fadadas a conflitar umas com as outras, é necessário que as regras institucionais que definem essas liberdades devam ser ajustadas de modo que se encaixem num sistema coerente de liberdades garantido igualmente a todos os

15. RAWLS, J. O liberalismo político. Tradução de Álvaro de Vita. São Paulo: WMF Martins Fontes, 2011, p. 345.

16. Idem, ibidem.

17. Idem, p. 346. 
cidadãos, sistema que deve estar aberto a revisões e adaptações conforme mudem as condições sociais necessárias para seu exercício duradouro, respeitando a esfera de aplicação de cada liberdade. ${ }^{18}$

Rawls continuará a manter a tese da prioridade da liberdade no sentido de que uma liberdade só pode ser limitada ou negada em nome de uma outra ou de outras liberdades fundamentais, e nunca por considerações de bem-estar geral ou por valores perfeccionistas. Sendo que as liberdades fundamentais podem ser limitadas quando entram em choque entre si, nenhuma delas pode ser considerada absoluta. Para justificar a prioridade das liberdades básicas Rawls esclarece qual o conceito de pessoa que está na base do liberalismo político. Além de serem vistas como cidadãos livres e iguais, as pessoas são tidas como cidadãos que possuem duas faculdades (ou capacidades) morais: a de terem um senso de justiça e a de formar, buscar e revisar uma concepção racional do bem. A lista de liberdades básicas sugerida por Rawls representa as condições sociais fundamentais para o desenvolvimento adequado e exercício pleno dessas duas capacidades da pessoa durante a vida inteira, fundamentais para o desenvolvimento de um senso de independência pessoal e de autorrespeito.

Mas, como justificar a própria ideia de pessoa? Certamente, afirma Rawls, existem muitos aspectos de nossa natureza que poderiam ser considerados como significativos para caracterizar a natureza humana: o bomo politicus, o bomo economicus, o bomo faber. O que justifica o conceito de pessoa adotado por Rawls é o próprio propósito da justiça como equidade:

o objetivo é formular uma concepção de justiça política e social que seja afim às convicções e tradições mais arraigadas de um Estado democrático moderno. O sentido de fazer isso está em verificar se temos como resolver o impasse de nossa história política recente, a saber, o de que não existe acordo sobre como as instituições sociais básicas devem se organizar para se conformar à liberdade e à igualdade dos cidadãos como pessoas. ${ }^{19}$

18. Essa indeterminação e o conflito entre as liberdades são resolvidos não pela teoria, mas pelo poder político, exercido segundo um princípio liberal de legitimidade baseado na razão pública. Cf. WERLE, D. L. Liberdades básicas, justificação pública e poder político em John Rawls. Dissertatio, v. 34, 2011, pp. 183-207.

19. RAWLS, J. O liberalismo político, p. 355. 
À luz desse propósito, o conceito de pessoa é justificado de duas formas: como uma ideia intuitiva presente na cultura política pública de uma democracia constitucional e como uma ideia da razão prática. ${ }^{20} \mathrm{O}$

20. O construtivismo político "afirma que, uma vez que se alcance o equilíbrio reflexivo, se é que isso é possível, os princípios de justiça política (conteúdo) podem se apresentar como o resultado de certo procedimento de construção (estrutura). Nesse procedimento, tal como modelado na posição original, agentes racionais, na condição de representantes dos cidadãos e sujeitos a condições razoáveis, escolhem os princípios públicos de justiça que devem regular a estrutura básica da sociedade. Esse procedimento - é o que conjeturamos - expressa todas as exigências relevantes da razão prática e mostra como os princípios de justiça resultam dos princípios da razão prática em conjunção com concepções de sociedade e de pessoa, concepções que constituem, elas próprias, ideais da razão prática". Idem, p. 106-107. Noutra passagem, Rawls reforça essa ideia: "podemos dizer, então, que as concepções de sociedade e de pessoa, e o papel público dos princípios de justiça são ideias da razão prática. Não só adotam uma forma que a razão prática requer para sua aplicação, como também proporcionam o contexto no qual questões e problemas práticos se apresentam. (...) Sem as ideias de sociedade e de pessoa, não há lugar para as concepções do justo e do bom. Essas ideias são tão fundamentais quanto as de juízo e inferência e quanto os princípios da razão prática". Idem, p.130. Essas passagens indicam que a ancoragem histórica da dimensão kantiana não redunda numa concepção conservadora e contextualista da justiça, ou numa espécie de concepção realista da moral. Como se sabe, Rawls se opõe expressamente ao realismo moral. O construtivismo kantiano sustenta que a objetividade moral deve ser compreendida segundo um ponto de vista social construído adequadamente que todos poderiam aceitar. Fora do procedimento de construção dos princípios de justiça, não existem fatos morais. Como dito acima, esse procedimento é construído segundo ideias de sociedade e de pessoa que são simultaneamente ideias da razão prática - e, como tais, pressupostos indispensáveis na formação do juízo moral imparcial - e ideias intuitivas implícitas na cultura política das sociedades democráticas modernas. Portanto, Rawls parece ter em mente um procedimento complexo de justificação que procurar reunir, na base comum da ideia fundamental de sociedade como sistema de cooperação social equitativo e de pessoa moral livre e igual, uma interdependência "dialética" entre o ponto de vista moral do que é bom para todos e o ponto de vista do que é bom para nós. Trata-se de uma tentativa de mostrar que os princípios de justiça podem ser justificados "em todos os níveis de generalidade". Cf. WERLE, D. L. Justiça e democracia. Ensaios sobre Jobn Rawls e Jürgen Habermas. São Paulo: Esfera Publica, 2008. 
conceito de pessoa é considerado como parte de uma concepção de justiça política e social, diz como os cidadãos devem ver a si mesmos e uns aos outros em suas relações políticas e sociais, da maneira especificada pela estrutura básica da sociedade. Este é o objeto primeiro da justiça, e abrange, com vimos, as principais instituições sociais - as relações familiares, o regime econômico, a especificação da propriedade e congêneres, a constituição política e a ordem legal, e como essas instituições se combinam para formar um sistema. O que é próprio da estrutura básica é que ela oferece o quadro para um sistema autossuficiente de cooperação para todos os objetivos essenciais da vida humana, objetivos esses realizados pelo grande número de associações e grupos no interior desse quadro. Ora, nesse sentido, pode-se dizer que, diferentemente da interpretação de Sen, o foco da justiça como equidade recai precisamente na situação real e na posição social e nas relações de socialização que determinam, em grande parte, a vida das pessoas concretas, e não apenas nas pessoas como indivíduos racionais abstratos que fazem escolhas orientados pelas suas preferências.

A estrutura básica da sociedade deve estar organizada de tal modo que as pessoas possam realizar-se como membros normais e plenamente cooperativos da sociedade. Uma vez que se adote a estrutura básica como objeto primeiro da justiça, a capacidade para a cooperação social com base no respeito mútuo é vista como fundamental. Para as pessoas serem vistas dessa maneira, Rawls atribui a elas duas capacidades morais - o senso de justiça (a disposição para seguir princípios de justiça e de dar e receber razões para justificá-los) e a concepção do bem (de formar, rever e perseguir certo plano racional de vida). $\mathrm{O}$ desenvolvimento dessas duas capacidades morais é uma condição necessária e suficiente para alguém ser considerado um membro pleno e igual na sociedade democrática. Essas duas capacidades morais constituem a base da cidadania igual, que implica que as pessoas possam participar efetivamente da cooperação social voltada para a vantagem mútua, mas com base no respeito mútuo, e com a disposição de respeitar os termos equitativos e apropriados de cooperação.

Diante disso, "o problema de especificar as liberdades fundamentais e de justificar sua prioridade pode ser entendido como o de determinar termos equitativos apropriados de cooperação com base no respeito mútuo". ${ }^{21}$ Até as guerras religiosas dos séculos XVI e XVII,

21. RAWLS, J. O liberalismo político, p. 303. 
esses termos equitativos eram muito restritos: a cooperação social com base no respeito mútuo era considerada impossível entre aqueles que professavam uma fé diferente ou uma concepção do bem diferente. $\mathrm{O}$ liberalismo nasce neste contexto com o desenvolvimento de diversos argumentos a favor da tolerância religiosa. No século XIX, com Constant, Tocqueville e Mill, a moralidade política liberal foi aprimorada tendo em vista o contexto do Estado democrático moderno em nascimento. Um dos pressupostos centrais do liberalismo

é que cidadãos iguais têm concepções do bem diferentes e até mesmo incomensuráveis e irreconciliáveis. Em uma sociedade democrática moderna, a existência de modos tão diversos de vida é vista como uma condição normal, que só poderia ser abolida pelo uso autocrático do poder estatal. ${ }^{22}$

A moralidade política liberal aceita esse pluralismo de concepções do bem como um fato da vida moderna, considera-o como algo desejável desde que a pluralidade possa ser acomodada num sistema de liberdades fundamentais iguais, de modo que sejam realizados os muitos benefícios da diversidade humana. Uma teoria da justiça deve fornecer princípios justificados de modo razoável e público a fim de que a união social não esteja fundamentada "em uma concepção do bem tal como dada por uma fé religiosa comum ou por uma doutrina filosófica, e sim em uma concepção pública e compartilhada de justiça apropriada à concepção dos cidadãos como pessoas livres e iguais em um Estado democrático". ${ }^{23} \mathrm{O}$ ideal político a ser realizado no mundo social é o da autonomia plena dos cidadãos: "a autonomia plena inclui não apenas essa capacidade de sermos racionais, mas também a de promover nossa concepção do bem de forma compatível com o acatamento dos termos equitativos de cooperação social, isto é, os princípios de justiça". ${ }^{24}$

Como sabemos, Rawls elabora um procedimento complexo de justificação que abarca diferentes níveis de generalidade para justificar a escolha dos princípios de justiça: o procedimento de deliberação e escolha dos princípios na posição original e o método do equilíbrio reflexivo cujo ápice é o consenso sobreposto. Mas mais do que um

22. Idem, pp. 359-360.

23. Idem, p. 360.

24. Idem, p. 362. 
procedimento, Rawls introduz elementos substantivos na justificação dos princípios: os bens primários (ou bens básicos).

A ideia principal é que os bens primários são escolhidos perguntando-se por aquelas coisas que em geral são necessárias como condições sociais e meios polivalentes para capacitar as pessoas a realizar suas concepções determinadas do bem e a desenvolver e exercer suas duas faculdades morais, [o que] pressupõe vários fatos gerais sobre as necessidades e capacidades humanas, suas fases características e seus requisitos de desenvolvimento, suas relações de interdependência social e outros fatores. ${ }^{25}$

Os bens primários são: a) as liberdades fundamentais, como condições institucionais essenciais e necessárias para o desenvolvimento e exercício pleno e bem informado das duas capacidades morais dos cidadãos; são indispensáveis para a proteção de um amplo leque de concepções específicas do bem; b) a liberdade de movimento e de escolha de ocupação num contexto de oportunidades variadas, que permitem a realização de diversos fins últimos e a possibilidade de levar a cabo uma decisão de revisá-los e mudá-los, se o desejarmos; c) os poderes e prerrogativas de posições e cargos de responsabilidade, que abrem espaço para várias capacidades sociais e de autonomia do self $_{i}$ d) renda e riqueza, entendidos como meios polivalentes necessários para realizar direta ou indiretamente uma grande variedade de fins, quaisquer que sejam; e) as bases sociais do autorrespeito, que incluem aqueles aspectos das instituições básicas em geral essenciais para que os cidadãos tenham um vigoroso sentimento de seu próprio valor como pessoas, e para que sejam capazes de desenvolver e exercer suas capacidades morais e de promover seus objetivos e fins com autoconfiança.

$\mathrm{O}$ argumento de Rawls visa mostrar que "as liberdades básicas são efetivamente, bens primários", ${ }^{26}$ e sua importância é justificada enquanto condições formais e materiais necessárias ao desenvolvimento da autonomia plena das pessoas como cidadãos. Em outros termos, as liberdades fundamentais e sua prioridade e o valor equitativo das liberdades políticas são justificadas tendo em vista sua importância no desenvolvimento das duas capacidades morais que caracterizam os

25. Idem, p. 364.

26. Idem, p. 366. 
cidadãos livres e iguais de uma sociedade democrática e assim são fundamentais para estabilizar uma cooperação social justa.

O que eu gostaria de destacar nessa argumentação é que Rawls não está pensando apenas na questão redistributiva-alocativa, mas principalmente nas bases sociais do autorrespeito. As liberdades fundamentais desempenham um papel importante na promoção do autorrespeito, elemento fundamental para explicar como os indivíduos adquirem um sentido interno de sua autonomia. ${ }^{27}$

\section{A estrutura básica e as bases sociais do autorrespeito}

Rawls define o autorrespeito a partir de dois aspectos:

Primeiro, essa ideia contém o sentido que a pessoa tem de seu próprio valor, sua firme convicção de que vale a pena realizar sua concepção de seu bem, seu projeto de vida. E, em segundo lugar, o autorrespeito implica uma confiança na própria capacidade, contanto que isso esteja ao alcance da pessoa, de realizar as próprias intenções. ${ }^{28}$

Ele se baseia em nossa autoconfiança enquanto membros plenamente cooperativos da sociedade, proporcionando um sentimento seguro do próprio valor, uma convicção firme de que vale a pena procurar realizar sua própria concepção do bem. Ele depende de e é incentivado por certas características públicas das instituições sociais

27. Uma série de intérpretes têm acentuado o papel de justificação que a ideia de autorrespeito desempenha na teoria da justiça de Rawls. Cf. COHEN, J. Democratic equality. Ethics, v. 99, n. 4, 1989, pp. 727-51; EYAL, N. 'Perhaps the most important primary good': self-respect and Rawls's principles of justice. Politics, Pbilosopby \& Economics, v. 4, n. 2, 2005, pp. 195-219; KEAT, R.; MILLER, D. Understading justice. Political Theory, v. 2, n.1, 1974, pp. 3-31; MASSEY, S. Is self-respect a moral or a psychological concept? Ethics, v. 93, n. 2, 1983, pp. 246-61; MILLER, D. Democracy and social justice. British Journal of Political Science, v.8, n.1, 1978, pp. 1-19; NIELSON, K. Radical egalitarian justice: justice as equality. Social Theory and Practice, v. 5, n.2, 1979, pp. 209-26; SHUE, H. Liberty and self-respect. Etbics, v. 85, n.3, 1975, pp. 195-203; ZAINO, J. Self-respect and rawlsian justice. Journal of Politics, v. 60, n. 3, 1998, pp. 737-53.

28. RAWLS, J. Uma teoria da justiça. Tradução de Jussara Simões e revisão técnica e da tradução de Álvaro de Vita. São Paulo: Martins Fontes, 2008, p. 544. 
básicas, de como elas funcionam juntas e como se espera que as pessoas aceitem esses arranjos, considerem e tratem umas às outras. Isso porque o sentimento de nosso próprio valor, assim como nossa autoconfiança, depende do respeito e da reciprocidade que os outros demonstram ter por nós, pois "se não tivermos a percepção de que nossos esforços são respeitados por eles, é difícil, se não impossível, manter a convicção de que vale a pena promover nossos objetivos" ${ }^{\prime 29}$

Rawls esclarece que já no nível mais fundamental os indivíduos exigem a aprovação dos outros: o autorrespeito é construído primeiramente na tenra infância, quando os pais afirmam o valor de seus filhos ao expressarem o desejo de cuidar e encorajar suas atividades. ${ }^{30}$ No contexto mais amplo das instituições sociais, medimos o reconhecimento dos outros por nossa personalidade tomando como referência o status ou nosso lugar na cooperação social. Como é impossível assegurar o autorrespeito dos indivíduos pela igualdade de status em todos os níveis possíveis, Rawls argumenta, num primeiro nível, que a distribuição igual de direitos e liberdades fundamentais fornece uma igualdade de status que satisfaz a necessidade de autorrespeito nos âmbitos mais fundamentais:

a base do autorrespeito em uma sociedade justa não está, então, na parcela de renda que a pessoa tem, mas na distribuição publicamente afirmada dos direitos e das liberdades fundamentais. E, sendo essa distribuição igual, todos têm um status semelhante e garantido ao se reunirem para tratar dos assuntos comuns da sociedade em geral. Ninguém se inclina a ultrapassar a afirmação constitucional de igualdade para alcançar outros meios políticos para garantir o próprio status. Nem, por outro lado, os membros dessa sociedade estão dispostos a aceitar menos do que uma liberdade igual. ${ }^{31}$

A aposta de Rawls é que as liberdades iguais possibilitam a criação de um ambiente associativo rico e diversificado no qual os indivíduos podem cultivar e adquirir confiança em suas capacidades e habilidades, uma parte necessária para terem um senso seguro de seu próprio valor. Em suma, são as liberdades iguais fundamentais que asseguram as condições sociais e políticas que tornam possível que os

29. Idem, p. 219.

30. Idem, p. 572.

31. Idem, p. 672. 
cidadãos expressem seu respeito mútuo uns pelos outros enquanto indivíduos razoáveis e dignos de confiança, assim como seu reconhecimento do valor que todos os cidadãos atribuem à própria forma de vida. Elas servem ao propósito público comum de assegurar a justiça a cada cidadão, enquanto pessoa livre e igual, em uma base de respeito mútuo, fazendo com que os vínculos de reciprocidade se estendam à sociedade como um todo.

Mas, é claro, as liberdades fundamentais não são meras formalidades. A concepção da justiça como equidade preocupa-se, principalmente no segundo princípio, com os meios materiais necessários para os cidadãos usarem efetivamente suas liberdades iguais e realizarem seus planos de vida. Muitos argumentaram, principalmente os democratas radicais e os socialistas, que, embora possa parecer que os cidadãos são efetivamente iguais, são demasiado grandes as desigualdades sociais e econômicas e que aqueles com maior riqueza e responsabilidade podem controlar a elaboração legislativa em benefício próprio.

É justamente por ter em vista esse tipo de assimetria no uso efetivo das liberdades que Rawls faz a distinção entre liberdades fundamentais e o valor das liberdades. As liberdades fundamentais especificam os direitos e deveres institucionais entre os cidadãos. Obviamente a falta de informação, a pobreza e a ausência de meios materiais em geral impedem as pessoas de exercerem seus direitos e de tirar proveito dessas possibilidades. São fatores que atingem o valor das liberdades, isto é, o proveito que as pessoas tiram de suas liberdades. Embora as liberdades fundamentais sejam as mesmas para todos os cidadãos, o valor da liberdade não é o mesmo para todos. Para tornar mais efetivo o uso das liberdades, Rawls confere atenção especial à dimensão da autodeterminação política. Apenas as liberdades políticas merecem um tratamento especial por parte de Rawls, "ao incluir no primeiro princípio de justiça a garantia de que às liberdades políticas, e apenas a elas, se assegure o que denominei seu 'valor equitativo"', ${ }^{32}$ no sentido de que todos os cidadãos tenham uma oportunidade equitativa de assumir um cargo público e influenciar o resultado de decisões políticas.

A garantia do valor equitativo das liberdades políticas tem como principal finalidade assegurar "a cada cidadão um acesso equitativo e aproximadamente igual ao uso de recursos públicos destinados a pro-

32. RAWLS, J. O liberalismo político, p. 387. 
mover um propósito político definido, a saber, os recursos públicos especificados pelas normas e pelos procedimentos constitucionais que governam o processo político e controlam o acesso a posições de autoridade política". ${ }^{33}$ Uma vez que consideramos o papel peculiar do processo político na determinação das leis e políticas que devem regular a estrutura básica, torna-se mais evidente para Rawls que as liberdades políticas devem ser objeto da garantia especial do valor equitativo. Claro, Rawls não está afirmando que a vida política e a participação de todos no autogoverno sejam consideradas bens proeminentes para cidadãos plenamente autônomos. A valorização da participação política em si é uma concepção do bem entre outras. $\mathrm{O}$ que importa a Rawls é a ideia de um sistema de liberdades básicas iguais. "A garantia do valor equitativo para as liberdades políticas é incluída no primeiro princípio de justiça porque resulta essencial para que se produza legislação justa e também para assegurar que o processo político equitativo especificado pela Constituição esteja aberto a todos, em uma base de igualdade aproximada". ${ }^{34}$

As liberdades fundamentais especificam o status comum e garantido dos cidadãos iguais numa sociedade democrática bem ordenada. "A liberdade é um determinado padrão de formas sociais". ${ }^{35}$ Ela é produzida pelas instituições sociais, políticas e jurídicas da sociedade. A ênfase está na organização de uma sociedade justa e livre. Segundo uma sugestão de Albrecht Wellmer ${ }^{36}$, a compreensão que Rawls tem da realização das liberdades é muito próxima ao modo de Hegel entender a realização da ideia de liberdade na Filosofia do Direito. Uma vez que o objeto primeiro da justiça é a estrutura básica da sociedade - que abrange, como vimos antes, as instituições da família, da propriedade, do mercado e do rule of law - podemos ver no liberalismo político de Rawls uma concepção de justiça que abrange os vários momentos ou dimensões de realização de uma concepção universal de liberdade comum, que acabaria se concretizando numa eticidade democrática.

33. Idem, p. 388-389.

34. Idem, p. 391-392.

35. RAWLS, Uma teoria da justiça, p. 77.

36. WELLMER, A. Condiciones de una cultura democrática: sobre el debate entre 'liberales' y 'comunitaristas'. In: A. Finales de Partida: La Modernidad Irreconciliable. Tradução: Manuel Jímenez Redondo. Madrid: Cátedra, 1996, pp.77-101. 
Ela abrange diferentes esferas de autorrealização dos seres humanos. Mas diferente de Hegel, em Rawls a passagem do direito abstrato à eticidade concreta se daria de forma mais democrática, já que o princípio da liberdade igual conduz diretamente a um princípio de direitos iguais de participação política e de deliberação pública.

Nesse sentido, a questão da justiça não parece se resumir apenas à criação de condições de autorrealização ética dos indivíduos que asseguram a satisfação de suas necessidades e carências básicas. $\mathrm{O}$ objeto de uma teoria da justiça é antes a estrutura básica profunda da sociedade que produz e reproduz as carências e as vulnerabilidades das pessoas. Por conseguinte, a tarefa de uma teoria da justiça é fazer com que a própria estrutura básica da sociedade assegure às pessoas a possibilidade real de definirem social e politicamente sua vida em comum. Portanto, a questão central da justiça é também a questão do poder social e político. Não se trata de saber apenas quais "bens" devem ser legitimamente distribuídos para quem e sob quais razões, mas também de ver como os bens são produzidos socialmente e quem e como são definidas as regras de sua distribuição. ${ }^{37}$ Ao assumir a estrutura básica da sociedade - as principais instituições sociais, econômicas e políticas - como objeto da justiça, Rawls coloca no centro de sua teoria a questão política acerca da definição da estrutura de produção e de distribuição dos bens e da justificação pública do poder nas sociedades democráticas.

O enfoque de uma teoria crítica da justiça que evite tanto o caráter excessivamente abstrato alheio ao contexto quanto o particularismo de uma concepção de vida boa obcecada pelo contexto precisa considerar as necessidades e demandas que podem surgir dos contextos de socialização dos indivíduos e que podem ser justificadas publicamente segundo razões aceitáveis recíproca e universalmente em diferentes contextos normativos. Esta é muito mais uma tarefa prática do que uma tarefa teórica, que implica um momento irredutível da autonomia em todas as relações de justificação. Poder-se-ia dizer que ser uma pessoa que tem o direito à justificação é outro elemento constitutivo das bases sociais do autorrespeito. A questão central de uma teoria crítica da justiça não é promover a autorrealização ética ou a autonomia individual negativa dos indivíduos, mas sim

37. Cf. FORST, R. Kritik der Rechtfertigungsverbältnisse - Perspektiven einer kritischen Theorie der Politik. Frankfurt am Main: Suhrkamp, 2011. 


\section{Denílson Luis Werle}

fazer com que a estrutura básica da sociedade não determine arbitrariamente a vida das pessoas. Parece-nos ser esta também a preocupação que está na base do liberalismo político de Rawls: a justiça não tem a ver com a promoção da vida boa, mas com a primazia das liberdades básicas na organização da estrutura básica da sociedade que salvaguarda as pessoas das vulnerabilidades internas e externas relacionadas à autonomia, ao proporcionar, entre outras coisas, as bases sociais do autorrespeito.

\section{Referências}

BANKOVSKY, M. Social justice: defending Rawls' theory of justice against Honneth's objections. Pbilosopby \& Social Criticism, v. 37, n. 1, 2011, pp. 95-118.

COHEN, J. Democratic equality. Ethics, v. 99, n. 4, 1989, pp. 727-51.

CROCKER, D. Functioning and capability. The foundations of Sen's and Nussbaum's development ethic. Political Theory, v.20, n.4, 1992, pp. 584-611.

EYAL, N. 'Perhaps the most important primary good': self-respect and Rawls's principles of justice. Politics, Pbilosophy \& Economics, v. 4, n. 2, 2005, pp. 195-219.

FORST, R. Kritik der Rechtfertigungsverbältnisse - Perspektiven einer kritischen Theorie der Politik. Frankfurt am Main: Suhrkamp, 2011.

HART, H. L. A. Rawls on liberty and its priority. In: DANIELS, N. (ed.). Reading Rawls. Critical studies of A Theory of Justice. Oxford: Basil Blackwell, 1975, pp. 230-252.

HONNETH, A.; ANDERSON, J. Autonomy, vulnerability, recognition and justice. In: CHRISTMAN, J.; ANDERSON, J. Autonomy and the challenges to liberalism: new essays. Cambridge: Cambridge University Press, 2005, pp. 127-49.

KEAT, R.; MILLER, D. Understading justice. Political Theory, v. 2, n.1, 1974, pp. 3-31.

MASSEY, S. Is self-respect a moral or a psychological concept?. Ethics, v. 93, n. 2, 1983, pp. 246-61.

MILLER, D. Democracy and social justice. British Journal of Political Science, v.8, n.1, 1978, pp. 1-19.

NIELSON, K. Radical egalitarian justice: justice as equality. Social Theory and Practice, v. 5, n.2, 1979, pp. 209-26. 
NUSSBAUM, M. C. Women and buman development. The capabilities approach. Cambridge: Cambridge University Press, 2000.

RAWLS, J. Uma teoria da justiça. Tradução de Jussara Simões e revisão técnica e da tradução de Álvaro de Vita. São Paulo: Martins Fontes, 2008.

O liberalismo político. Tradução de Álvaro de Vita. São Paulo: WMF Martins Fontes, 2011.

SEN, A. Development as freedom. New York: Knopf Press, 1999.

A ideia de justiça. Tradução de Denise Bottmann e Ricardo Doninelli Mendes. São Paulo: Companhia das Letras, 2011.

SHUE, H. Liberty and self-respect. Ethics, v. 85, n.3, 1975, pp. 195-203.

WELLMER, A. condiciones de una cultura democrática: sobre el debate entre 'liberales' y 'comunitaristas'. In: WELLMER, A. Finales de Partida: La Modernidad Irreconciliable. Tradução: Manuel Jímenez Redondo. Madrid: Cátedra, 1996, p.77-101.

WERLE, D. L. Justiça e democracia. Ensaios sobre Jobn Rawls e Jürgen Habermas. São Paulo: Esfera Publica, 2008.

Liberdades básicas, justificação pública e poder político em John Rawls. Dissertatio, v. 34, 2011, pp. 183-207.

ZAINO, J. Self-respect and rawlsian justice. Journal of Politics, v. 60, n. 3, 1998, pp. 737-53.

ZINK, J. R. Reconsidering the role of self-respect in Rawls's A theory of Justice. The Journal of Politics, v. 73, n.2, 2011, pp. 331-344.

Recebido em 22.04.2014

Aceito em 21.05.2014 